\title{
An interview with Bill and Melinda Gates
}

\author{
Bill and Melinda Gates have led a profound transformation in the way we view the world's most pressing health \\ concerns, looking for effective ways to improve the lives of millions of people. Claire Pomeroy, president of the Albert \\ and Mary Lasker Foundation, spoke with them about their current concerns and plans to advance their agenda.
}

\begin{abstract}
You have dedicated yourselves to many projects, including vaccine development, nutrition support and family planning. How have these projects differed in their goals and impacts?

Bill Gates: Underlying everything we do is the plain fact that we have been uniquely privileged, and with that good fortune we have a responsibility to return what we have in the best way we know how. This is all the more true since our friend, Warren Buffett, pledged to contribute a majority of his fortune to the Gates Foundation. While our combined resources are significant, they are a drop in the bucket compared to what governments contribute to global health and development. So, we focus on areas where we believe we can have a catalytic impact, where we can bring together organizations that might not otherwise collaborate and where we are uniquely positioned to take risks that others are unable or unwilling to take. Melinda Gates: When we started the foundation, there were two questions that guided our decisions about where to invest. First, what are the areas of greatest need? And second, where can we have the greatest impact? This pointed us toward a set of issues in global health and development. It was clear, for example, that vaccines are an incredibly cost-effective way to reduce child deaths and disease, and we could invest in delivering the vaccines that already exist and in developing new vaccines. We got involved in agriculture as we learned how higher-yielding, disease-resistant seeds can help poor farmers put more food on the table and lift themselves out of poverty. In the past several years, I've been focused on making sure effective contraceptives are available to women in poor countries, so they can protect themselves and provide a better future for their children. All of these efforts require different strategic approaches, whether it's upstream research and development, innovative financing, building partnerships or advocacy. But no matter the details of how we invest, everything we do has one feature in common: helping lift the burden of poverty, hunger and disease for people who are struggling to improve their lives.
\end{abstract}

Many of us in the scientific community lament the apparent antiscience bias among some policy makers and segments of the general public. What specific steps do you think could be taken to engender greater support for science-based policy making?

BG: Personally, I'd like to see more of our leaders take a more scientifically minded, technocratic approach to solving our biggest problems. I know some people use the term 'technocratic' derisively, but I mean it in its most positive sense. We should be asking ourselves: "Given the things that the country wants to get done, what's the most efficient way to accomplish them?" In an area like our energy supply, the current course won't get us where we want to go. So, the debate should be focused on the choices that are available to us. What are the facts? What do the data tell us about what's working and what isn't?
As for how we encourage more people to embrace this kind of approach, I've found that people respond very positively to examples of where there has been success. If we show them examples of what has worked, they're more likely to take that same approach in the future.

My favorite success story of all time has science and the scientific method at its core. In the year I was born, more than 20 million children under the age of 5 died. Last year, that number was 6.9 million. More recently-over the past 13 years-the world has cut extreme poverty in half, cut in half the number of people who don't have safe drinking water, cut nearly in half the number of mothers who die during childbirth. This has been driven in part by the Millennium Development Goals, partly with the tools of science and partly by applying a scientific mindset that sets a goal, measures progress, studies the data, sees what's working, adjusts the plan and keeps on trying.

If all of us who care about saving lives speak up and tell these kinds of success stories-and if we emphasize the crucial role that scientific advances play in making them a reality - then I think we can drive the kind of change you're talking about.

One of Mary Lasker's goals was to increase funding for biomedical research, especially at the US National Institutes of Health. After many years of success, funding has recently stagnated. What can be done to increase support for this research?

MG: To underscore what Bill said about getting the word out, it's an issue of making sure that the funders, or the people who vote the funders into office, fully appreciate the impact that biomedical research has had on the world. The general perception of what science has accomplished does not match the reality. In the short period since we started the foundation, the world has developed vaccines to protect children from diarrhea and pneumonia, the two leading childhood killers. These vaccines are now available to poor countries through an organization called the GAVI Alliance, which means the benefits of science are spread more evenly across society.

Yet very few people are aware of these breakthroughs. Fewer still have seen a baby dying from pneumonia. Nobody who could see that baby and then understand how the pneumococcal vaccine prevents suffering would oppose funding for biomedical research. The key is drawing a line between the funds on one hand and the lifesaving difference they make on the other. It's incumbent upon those of us who have seen the difference firsthand to tell stories of impact so that Americans know what a bargain they're getting when they fund research. Scientists used to be heroes. They raced for the cure. They raced for space. We need to build a new popular narrative of what science can do for all of us. 
You are symbols of the power of innovation and entrepreneurship. Do you see the US continuing to lead in these areas? What new ideas might spur innovation to enhance global health?

BG: It's amazing how many fields of science can help the poor. Materials science can lead us to toilets that work for the 2.6 billion people who don't have access to clean sanitation today. Genetics can generate highyielding crops. Energy research can provide the poor with affordable energy that can also help mitigate climate change.

The US will continue to lead in areas like these as long as we continue making the kinds of investments that made us leaders in the first place. Among other things, that means the federal government needs to continue investing in basic scientific research. It also means making sure our universities continue to be the best and that they draw the most talented students in the world.

But the question of which countries are leaders in innovation is less important than the question of how we make sure innovations are developed and reach the people who need them. A mother in Botswana just wants the vaccines that will save her child's life. She doesn't care which country it came from.

So we need to keep drawing top scientists from many fields and many countries into this work. A few years ago, the foundation started a program called Grand Challenges in Global Health. The idea is to bring together scientists and others across disciplines and from different countries to tackle some of the biggest problems in global health. Their research efforts range from improving existing vaccines and discovering new ones to finding new ways to reduce infant and maternal mortality.

Is medical research today adequately addressing the most pressing needs for public-health research? What areas are most neglected? What research fields are most underserved?

MG: Although there is excellent medical research taking place in many different areas, it unfortunately can never quite keep up with the need. While it's true that women need better access to the contraceptives that exist today, we also need to develop new, better contraceptives.

The contraceptives available today were developed to serve the needs of women in Western countries, but they don't address the needs of women in many developing countries. In many homes, women encounter opposition from their husbands, who may not approve of their decision to plan for their families. This is one reason implants and injectable contraceptives are so popular in sub-Saharan Africa. Fortunately, new versions of

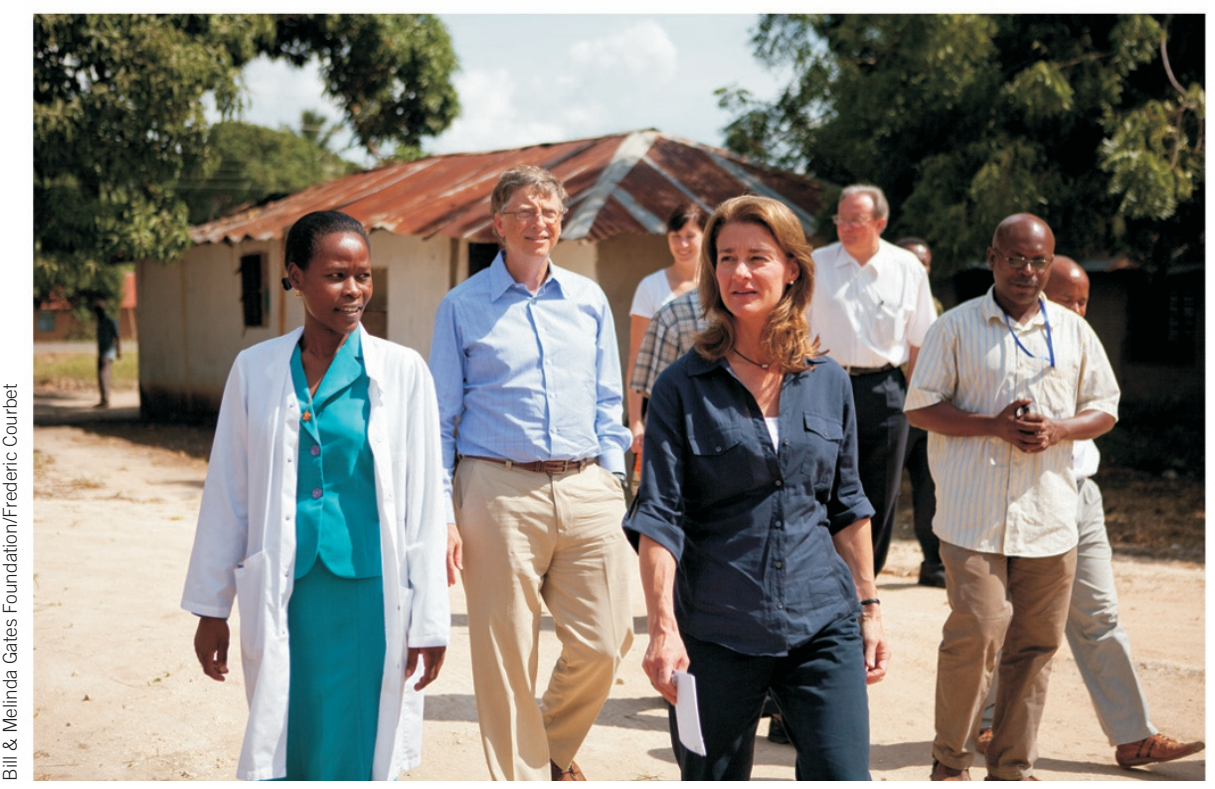

these methods show a lot of promise for increasing the use of contraceptives. Many women in rural areas also have concerns about side effects, and because they are married to men who travel to cities for long stretches looking for work, they don't use contraceptives regularly, but they need a product that works immediately when their husbands return home and lasts for only a short time. Now that family planning is back on the global agenda, hundreds of millions of women will have a much easier time providing a better future for themselves and their children.

Some would argue that the response to the HIV epidemic has created a paradigm shift wherein the world has recognized the rights of people to lifelong clinical treatment; but others have said that although this might well be an ideal, emphasizing treatment decreases the capacity of low-income countries to provide costeffective prevention strategies. Do you agree? How does the work of the Gates Foundation inform the response to this difficult dilemma?

BG: There are always going to be trade-offs and difficult decisions. But I don't see it as a zero-sum game. Whenever your resources are tight, the key is to make sure you're using them as efficiently as possible. For example, some HIV/AIDS interventions, including male circumcision and preventing mother-to-child transmission, are so cheap and effective that in endemic countries it is actually more expensive not to pursue them. But far too few people actually get access to these tools. So we can save a lot of lives efficiently by making sure they reach more people.

In the case of HIV, the 'treatment or prevention' question takes on an extra dimension because studies have shown that treatment is prevention. Putting people with HIV on antiretroviral drugs makes them far less likely to pass the virus on to others. The cost of the drugs themselves has come down remarkably over the past few years, but the big opportunity is in driving down the cost of delivering them. That means minimizing personnel costs and simplifying testing regimes. Some countries are doing very smart things in this area, but we need to do more to find the best practices and spread them.

Of course, the ultimate solution would be an HIV vaccine. That's a long way off, and it's such a risky investment that it's hard for governments or businesses to put much money into it. So we have made the search for a vaccine our largest investment in HIV/AIDS. We also support innovative approaches to preventing the spread of the virus. And we're a big supporter of the Global Fund to Fight AIDS, Tuberculosis and Malaria, which works to prevent HIV and has helped millions of HIV-positive people get the drugs they need to survive.

Some would claim that most biomedical research investments have gone toward the molecular sciences, ignoring the crucial issue of behavior, whose science base has never developed the support it needs. Indeed, it is becoming increasingly clear that social factors-education, income, social support-are among the most powerful drivers of health. Should bio-behavioral research initiatives be increased? And if so, what key questions should they address?

MG: I hope we don't have to present the problem in 'either/or' terms. It is critical to continue conducting research into new products and technologies that can improve people's lives, like better vaccines, better seeds for farmers 


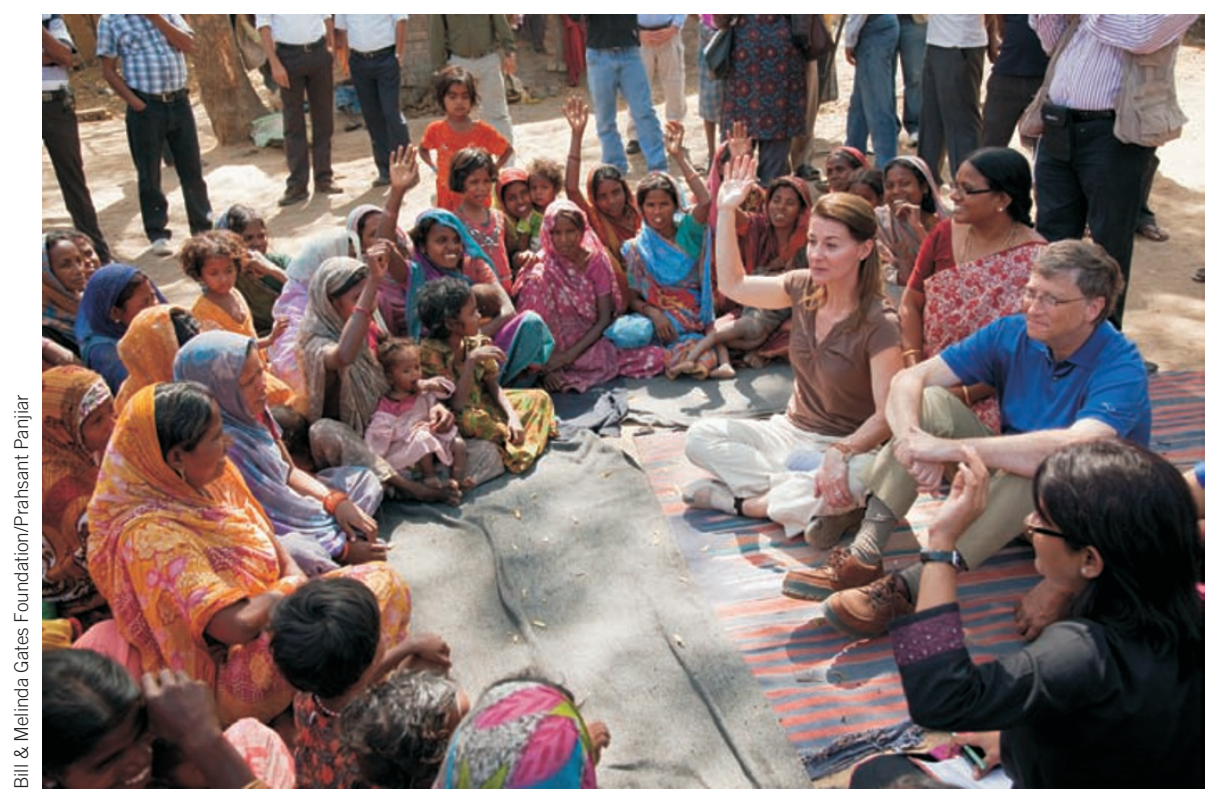

Many lifesaving discoveries have been made through medical research, but the benefits are often not accessible to everyone in the US, let alone around the globe. What new actions need to be taken to ensure that cost-effective biomedical breakthroughs are available to all?

BG: I think there are two problems with getting breakthroughs to the people who need them, and both are rooted in the unusual market dynamics of health care. First, diseases that have the greatest impact on the poor world are often ignored. It's understandable, as it isn't at all clear that there will be market for a drug or therapy in the developing world after the long and expensive process of development and testing. Meanwhile, diseases that touch the rich world present all sorts of business opportunities. So research into something like male pattern baldness gets an order of magnitude more research money than diseases that devastate the poor

and better contraceptives. At the same time, it's just as critical to study what it is about people and communities that leads them to adopt one seed over another, or to use contraceptives or not. The two go hand in hand, and I hope we are starting to see more sophistication on the behavioral side. In India, I've visited a behavior-change project in an area called Shivgarh. It works with young mothers to teach a few key newborn-care practices like immediate and exclusive breastfeeding and drying, and wrapping the baby. The results have been extraordinary, with newborn death rates declining by more than half in the study area. I've also been impressed with Tostan, a program started in Senegal, which has stopped female genital mutilation in more than 1,000 villages. Both of these examples illustrate that not every solution has to be high-tech. Innovation can also come in the form of low-cost, practical solutions that-if based on good research and applied correctly_can have immediate and long-lasting benefits. However, there are so many more questions we need to answer. For example, how do we scale behavioral changes? We have seen projects work in culturally specific contexts, but how do you spread those projects into other contexts? That is one of the key issues that behavioral research will have to grapple with in the near future. world, like drug-resistant tuberculosis or malaria.

We try to use our investments in global health to help correct these market bottlenecks. It takes partnerships with pharmaceutical companies, research institutions, nongovernment organizations (NGOs) and governments. As one example, we support financing mechanisms that pool funds from donors and make clear to pharmaceutical companies that they will be able to recoup their costs if they invest in diseases of the poor world.

The second problem is that many existing therapies don't reach the people who need them. While there may be a gap in health care in the US, there is a chasm in the poor world, where basic interventions like vaccines remain inaccessible to millions of children. For example, once a new vaccine is introduced in the wealthy world, it takes 10 to 15 years on average to reach low-income countries.

Here, too, it's partnerships that will make progress possible. Groups like the Global Fund and GAVI, which bring together NGOs, donor countries and affected nations, are important steps to address this inequity. But there are still many areas that cry out for attention. We have a lot more work ahead of us. 